\title{
АДРЕСНАЯ ДОСТАВКА ЛЕКАРСТВЕННЫХ НАНОПРЕПАРАТОВ В ПРИМЕНЕНИИ К МОДЕЛЯМ РАКА НА ДОКЛИНИЧЕСКОМ ЭТАПЕ ИССЛЕДОВАНИЙ
}

\author{
С. Марчио ${ }^{1,2}$, Ф. Буссолино ${ }^{1,2}$ \\ 1 Кафедра онкологии, Туринский университет, Кандиоло, Италия \\ 2 Институт онкологии (FPO-IRCCS), Кандиоло, Италия
}

\begin{abstract}
Несмотря на значительные успехи в терапии рака, большое число пациентов пока не может быть излечено. Представленные в обзоре стратегии преодоления этой проблемы активно разрабатываются по двум направлениям: 1) оптимизация диагностических протоколов для обнаружения опухолей на ранних стадиях; 2) разработка персонализированных средств терапии для увеличения эффективности и селективности лечения. Проводимые в последнее время исследования были направлены на рациональное внедрение обоих подходов, а их результаты внесли вклад в разработку нанопрепаратов, которые можно адресно доставлять к пораженным тканям в целях тераностики опухолей на доклинических моделях. Эти модульные наносистемы достаточно гибки и позволяют объединить визуализацию и таргетирование лекарств для применения в онкологии. Они могут служить базой для дальнейшего усовершенствования методов лечения рака.
\end{abstract}

Ключевые слова: наночастицы, адресная доставка лекарств, доклинические исследования, нанофармакология, онкология, тераностика

$\bowtie$ Для корреспонденции: Серена Марчио

Институт исследований и лечения рака, Университет Турина, 142 Km 3.95, Кандиоло, Италия, 10060; serena.marchio@ircc.it

Статья получена: 29.06.2018 Статья принята к печати: 21.08.2018

DOI: $10.24075 /$ vrgmu.2018.081

\section{TARGETED NANOMEDICINES FOR APPLICATIONS IN PRECLINICAL CANCER MODELS}

\author{
Serena Marchió ${ }^{1,2}$, Federico Bussolino ${ }^{1,2}$ \\ ${ }^{1}$ Department of Oncology; University of Turin; Candiolo, Italy \\ ${ }^{2}$ Candiolo Cancer Institute-FPO-IRCCS; Candiolo, Italy
}

\begin{abstract}
Despite substantial advancements in cancer management, a considerable proportion of patients cannot yet be cured. Strategies to address this open medical need are actively pursued and include two main approaches: 1) optimizing diagnostic protocols to detect tumors at early stages, and 2) designing personalized therapies to increase efficiency and selectivity of clinical interventions. Our recent work has been directed to a rationally-designed implementation of both approaches. Particularly, we have contributed to the development of nanomedicines that can be targeted to diseased tissues for theranostic purposes in preclinical models of human cancers. Such modular nanoscale systems proved to be versatile platforms to combine imaging and drug delivery for applications in the oncological field and could be a basis for future improvements.
\end{abstract}

Keywords: theranostic, cancer, targeted nanomedicines, preclinical models

$\square$ Correspondence should be addressed: Serena Marchio

Institute for Cancer Research and Treatment, University of Torino, 142 Km 3.95, Candiolo, Italy, 10060; serena.marchio@ircc.it

Received: 29.06.2018 Accepted: 21.08.2018

DOI: $10.24075 /$ brsmu.2018.081

Ранняя диагностика и эффективная терапия рака крайне важны для снижения заболеваемости и смертности от этой болезни. Чтобы добиться этих целей, нужно изучать и разрабатывать: 1) специсичные для каждой опухоли молекулы, которые могут служить как диагностическими маркерами, так и целями для таргетирования; 2) средства визуализации и доставки лекарств в пораженные участки тела, позволяющие эффективно проводить терапевтическое вмешательство, не затрагивая здоровые ткани. Несмотря на то что эти два подхода известны и широко обсуждаются, развитие персонализированной медицины идет довольно медленно, в частности из-за наличия малого числа подходящих молекулярных маркеров. Например, из 1500 белков, предложенных в качестве биомаркеров рака в 2000-2010 гг, не более 20 были допущены к исследованиям Управлением по контролю качества пищевых продуктов и медикаментов США (Food and
Drug Administration, FDA) [1]. В то же время применение нанотехнологий в медицине (наномедицина) оказывает огромное влияние на развитие терапии рака нового поколения, как показывает количество проводимых клинических и доклинических испытаний с использованием этих технологий [2, 3]. Нанопрепарат — это терапевтический, диагностический или комбинированный (тераностический = терапевтический + диагностический) агент, помещенный внутрь наночастицы $(H Ч)$ или присоединенный $\mathrm{K}$ ней. Н4 способствует лучшему биораспределению агента, повышает его эффективность или понижает токсичность. В ходе работы были идентифицированы новые биомаркеры и изучено применение нанопрепаратов таргетированной доставки для визуализации рака (флуоресцентные НЧ) и его терапии (содержащие лекарства липосомы) на моделях для доклинических исследований. В настоящем обзоре мы кратко описываем основные результаты этой работы. 


\section{Прицельная молекулярная визуализация метастатического колоректального рака}

Наша исследовательская группа описала ранее неизвестный комплекс интегрина альфа-6 и Е-кадгерина, который присутствует на поверхности раковых клеток толстой кишки и отсутствует у нормальных клеток толстой кишки [4]. Мы идентифицировали также специфический лиганд к этому рецепторному комплексу, а именно ангиопоэтинподобный белок 6 - фактор, в больших количествах вырабатываемый здоровой печенью и физиологически вовлеченный в метаболизм липидов. Данный комплекс рецептора и лиганда участвует во вторичном распространении опухолей: раковые клетки толстой кишки выделяют рецептор, нормальные клетки печени секретируют лиганд, а их взаимное распознавание позволяет раковым клеткам заселить печень, в итоге образовывая там скопление метастазов [4].

Кроме того, описаны два пептида-аналога ангиопоэтинподобного белка 6, которые связывают комплекс интегрин альфа-6/Е-кадгерин. Эти пептиды, имеющие последовательность CGIYRLRS и CGVYSLRS (однобуквенный код аминокислот), благодаря способности конкурировать с ангиопоэтинподобным белком 6 при связывании рецепторного комплекса (и таким образом ингибировать метастазирование в печень) представляют собой потенциальное средство для идентификации клеток опухолей, которые вырабатывают как интегрин альфа-6, так и Е-кадгерин [4]. Мы использовали их способность к связыванию при создании нанопрепаратов для визуализации рака [5]. В данном исследовании были использованы кремниевые НЧ, которые имеют подходящий токсикологический профиль и хорошую биосовместимость in vivo в сочетании с легкостью выполнения манипуляций in vitro [6, 7]. Были созданы модульные наносистемы, чтобы получить визуализационную платформу, состоящую из флуоресцентных кремний-полиэтиденгликолевых (ПЭГ) НЧ, на поверхности которых присутствует пептид CGIYRLRS или CGVYSLRS. Такие НЧ имеют ядро из диоксида кремния, к которому добавлены один или несколько флуоресцентных красителей на основе алкоксисиланов; ядро заключено в мицеллу сополимера Pluronic ${ }^{\circledR} 127$. Иными словами, они состоят из полиэтиленгликолевой оболочки, внутри которой находится ядро из диоксида кремния с добавлением красителя. Полиэтиленгликоль снаружи работает как стандартный полимер для обеспечения малозаметности, способствуя стабильной дисперсии в физиологических условиях и препятствуя поглощению клетками фагоцитарной системы. Кроме того, полиэтиленгликолевые хвосты могут быть дериватизированы для обеспечения возможности ковалентного присоединения пептидов направленного действия. Наши кремниевые НЧ имеют диаметр ядра SPN $11 \pm 3$ нм и гидродинамический диаметр 23 нм, они содержат краситель родамин A (Rhod), цианин 5 (Су5) (одноцветные) или оба (двухцветные). Их специсичность была сначала изучена ex vivo на образцах метастазов печени пациента в сравнении с образцами нормальной печени и первичного рака толстой и прямой кишки (рис. 1). Срезы образцов замороженных человеческих тканей инкубировали с контролем (без метки) и с двухцветными (Rhod + Cу5) кремниевыми Н4 с пептидной меткой. Селективность НЧ оценивали методом конфокальной микроскопии (визуализация, рис. 1А-Г; количественные показатели, рис. 1Д), выявляя специфическое связывание кремниевых H4 CGIYRLRS- и CGVYSLRS-(Rhod + Cy5) с клетками метастазов печени (рис. 1Б) и проводя сравнение с образцами ткани нормальной печени (рис. 1А) и толстой кишки (рис. 1В), а также первичной опухоли (рис. 1Г).

Кремниевые Н4 исследовали in vivo на модельных мышах с псевдо-метастатической опухолью (раковые клетки толстой кишки человека имплантировали в селезенку мышей с диабетом без ожирения/тяжелым комбинированным иммунодефицитом; рис. 2). Имеющим опухоли мышам ввели контроль и меченые кремниевые Н4. Сигнал был зарегистрирован после того, как время циркуляции превысило 1 ч. Через 6 ч мы заметили значительное снижение фоновой флуоресценции, и величина соотношения сигнал-фон оставалась неизменной после 16 и после 24 ч. Это позволяет предположить, что освобождение лишенных метки НЧ сопровождается накоплением меченых кремниевых НЧ в метастатических очагах, обеспечивая большой временной интервал для переноса метода в клинику. Флуоресцентная визуализация методом стереомикроскопии и конфокальной микроскопии подтвердила специфичное накопление в метастазах кремниевых H4 (Rhod)-CGIYRLRS (рис. 2A, Г, Ж, 3), Н4 (Сy5)-CGIYRLR (pиc. 2Б, Д, И, К) и НЧ (Rhod-Cy5)-CGIYRLRS (рис. 2B, Е, Л, М, Н, О). Трехмерная реконструкция нескольких конфокальных микрофотографий показала, что меченые кремниевые НЧ располагаются очень близко к кровеносным сосудам опухоли (рис. 2П, Р).

Интраоперационно фрлуоресцентные индикаторы начинают применять при раке простаты, желудка, мочевого пузыря и яичников [8-11]. Возможна флуоресцентная
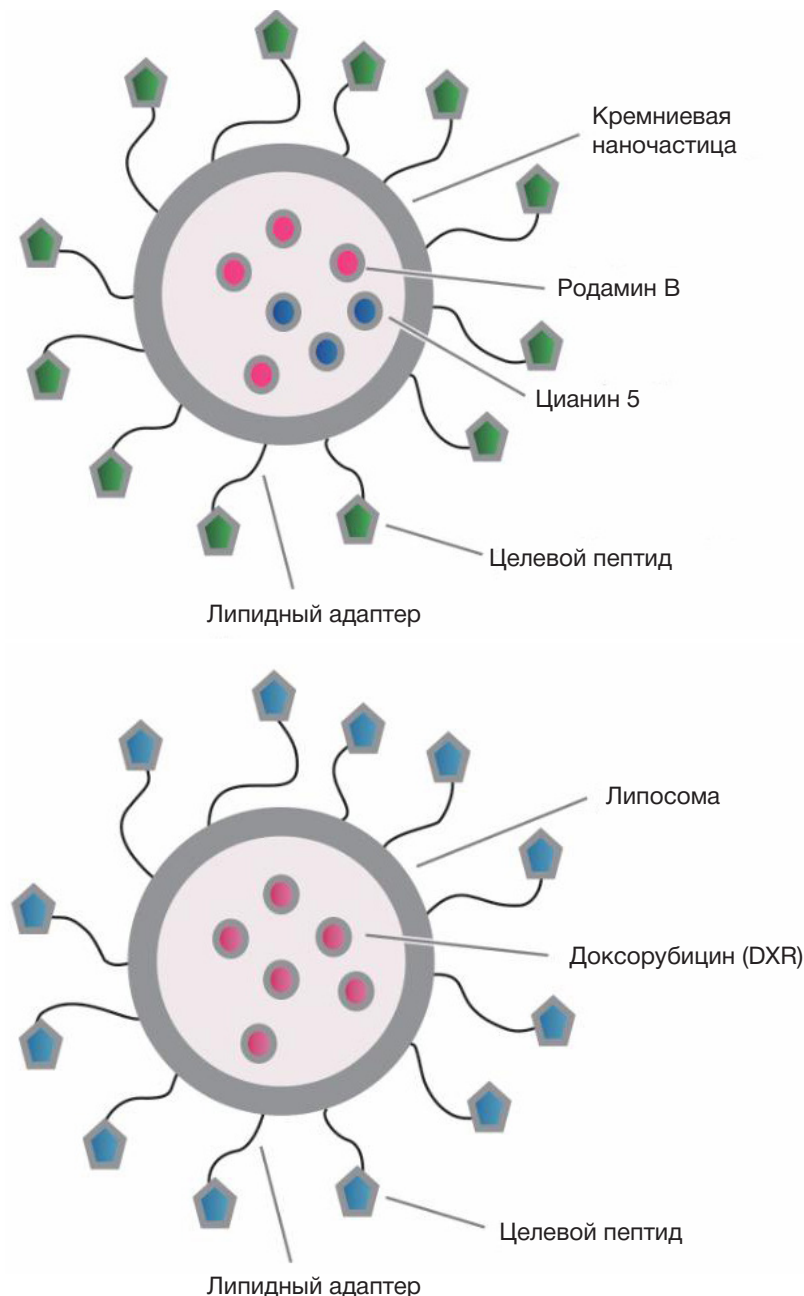
визуализация наружных злокачественных образований, а именно немеланомных опухолей кожи [12]; уже разработаны эндоскопические системы флуоресцентной визуализации, предназначенные для применения при раке толстой и прямой кишки [13]. Все эти системы основаны на использовании лишенных метки фрлуоресцентных индикаторов, в то время как наши кремниевые НЧ имеют дополнительную функцию молекулярного нацеливания, что является еще одним доказательством клинической релевантности.

\section{Целевая доставка препарата при метастатической нейробластоме}

В последние годы были идентифицированы пептиды с уникальными функциями нацеливания для применения
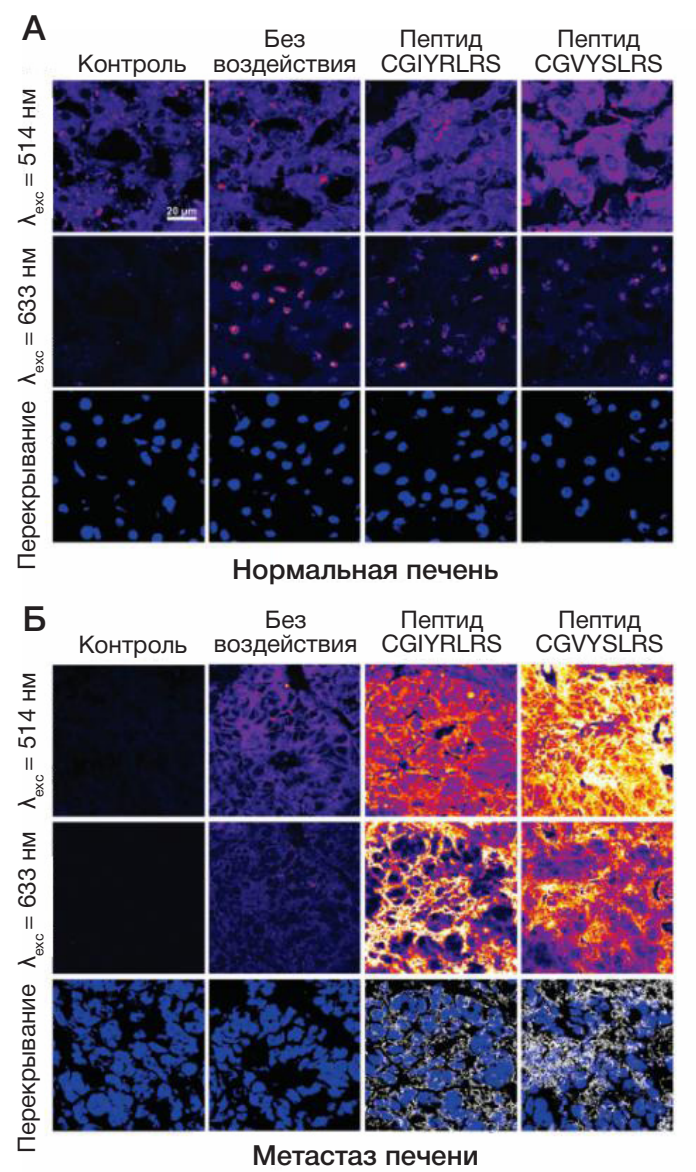

B

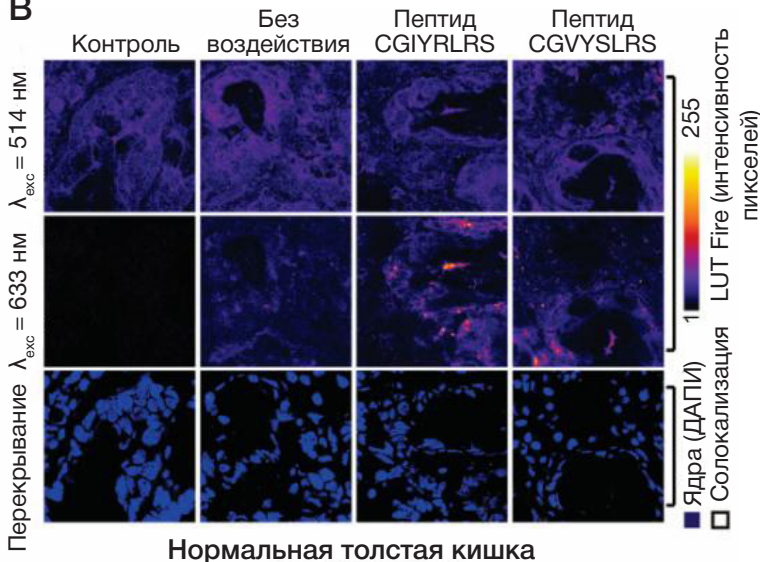

Нормальная толстая кишка

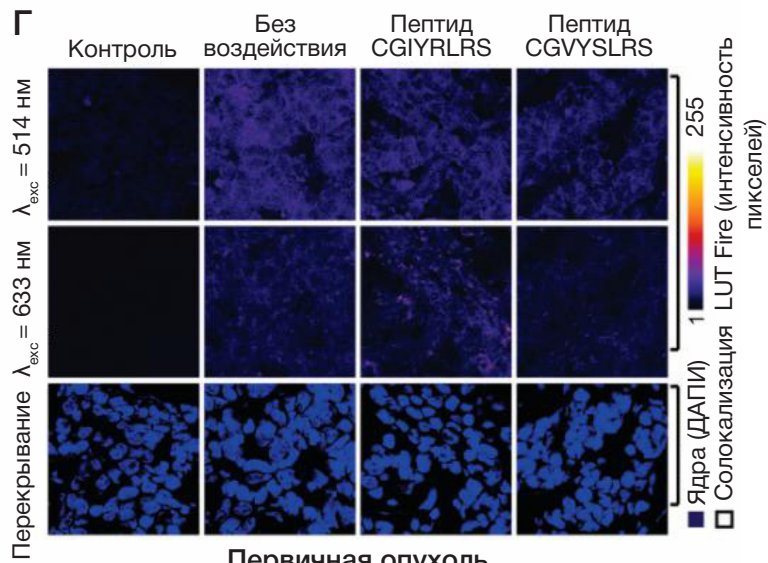

Первичная опухоль

Д

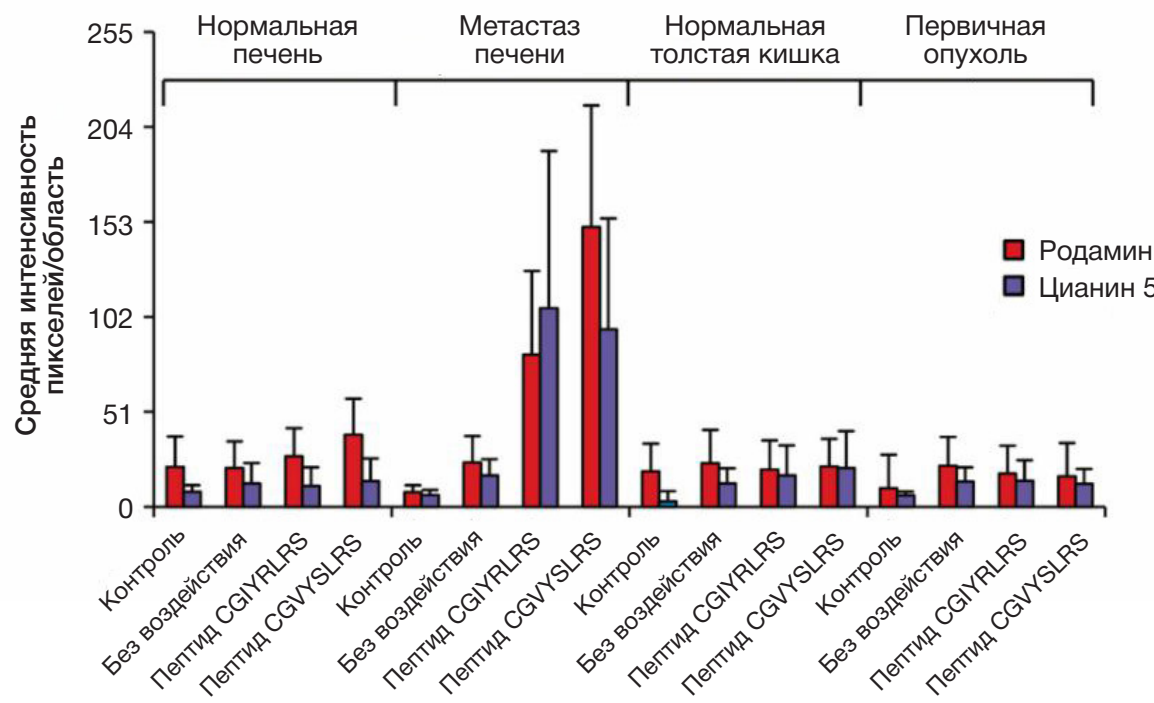

Рис. 1. Замороженные срезы нормальной печени (А), метастазов печени (Б), нормальной толстой кишки (В) и первичной опухоли (Г), которые были зафиксированы в 4\%-м растворе формальдегида, после чего их инкубировали с лишенными метки кремниевыми наночастицами CGIYRLRS- или CGVYSLRS-(Rhod+Cy5) в течение 4 ч при комнатной температуре. После промывания испускаемую кремниевыми НЧ флуоресценцию проанализировали методом конфокальной микроскопии, а ответ преобразовали в ложно-цветное изображение LUT Fire для быстрой визуализации. Ядра были окрашень 4', 6-диамидин-2-фенилиндолом (ДАПИ). Солокализованные пиксели идентифицировали с помощью программного обеспечения ImаgеЈ. В ходе экспериментов, показавших схожие результаты, использовали образцы, отобранные у 10 пациентов с метастатическим колоректальным раком; на примере представлены изображения тканей пациента \#Р85. (Д) Количественно связывание кремниевых НЧ выражается как интенсивность испускаемых пикселей после облучения на 514 нм (Rhod) и 633 нм (Су5) и представляет собой среднее значение для пяти изображений каждой ткани. (По данным: Soster и др. [5].) 
в лечении опухолей. Из них CPRECES [14] и CNGRC [15] (однобуквенный аминокислотный код) с высокой селективностью связываются с маркерами эндотелиальных периваскулярных опухолей аминопептидазами А (APA) и N (APN) соответственно, поэтому они оптимальны для применения в доставке препаратов in vivo через кровяное русло.

Эти два пептида использовали в первом исследовании, целью которого была доклиническая оценка осуществимости доставки нанопрепаратов направленного дейстия для доксорубицина на моделях нейробластомы первой стадии [16]. Для этого были получены синтетические версии обоих пептидов путем слияния человеческого фактора некроза опухолей с коротким линкером КY (однобуквенный аминокислотный код) и последующего присоединения к полиэтиленгликолевым стелс-липосомам, в состав которых входят дистеароилфосфатидилэтанол-
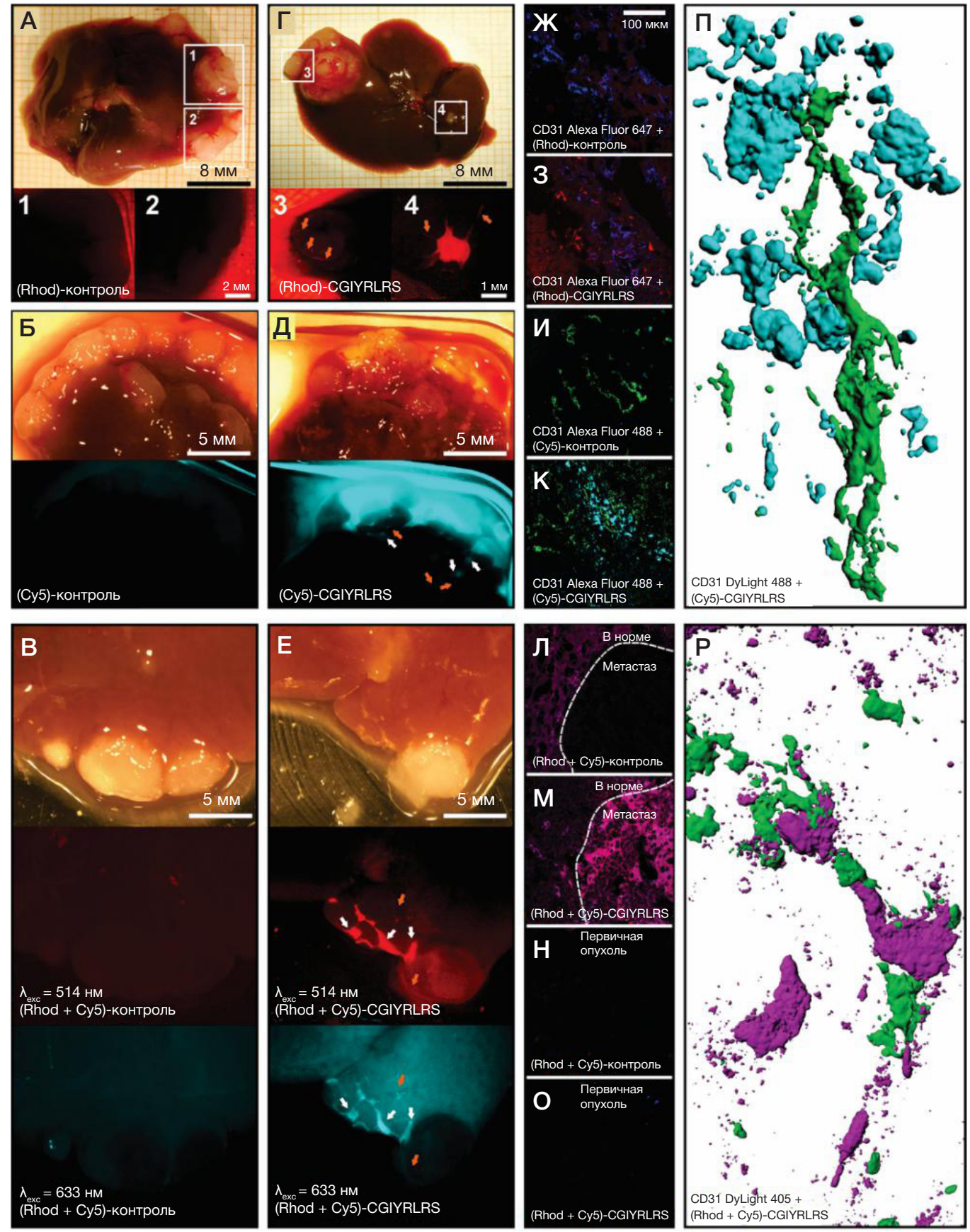

Рис. 2. Мышам с диабетом без ожирения/тяжелым комбинированным иммунодефицитом, имеющим первичные опухоли и множественные метастазы в печени, ввели одноцветные кремниевые НЧ (контроль (А, Rhod; Б, Су5) или НЧ CGIYRLRS (Г, Rhod; Д, Сy5)), двухцветные НЧ (контроль (B) или HЧ CGIYRLRS (E)). Через 16 ч мышей усыпили, а извлеченные органы сфотографировали на цифровую камеру высокого разрешения, подкпюченную K флуоресцентному стереомикроскопу. На рис. Г, Д и Е оранжевыми стрелками отмечены кровеносные сосуды, проходящие через метастазы печени; на рис. Д и Е белыми стрелками с субмиллиметровой точностью отмечены скопления метастазов. Образцы одних и тех же тканей заморозили методом ОСТ, порезали на срезы толщиной 10 мкм и исследовали методом конфокального анализа одноцветной (контроль (Ж, Rhod; И, Cy5), CGIYRLRS (3, Rhod; K, Су5)) или двухцветной (контроль (Л), CGIYRLRS (М)) флуоресценции. Для визуализации кровеносных сосудов окрашивание CD31 было наложено на сигнал кремниевых Н4 и визуализировано с помощью вторичных антител Аlеха Fluог'647 (Ж3), Alexa Fluor ${ }^{\circledR} 88$ (И-K) и DyLightTM405 (Л-0), для перекрывания с сигналом Н4 (Rhod), (Су5) и двухцветных Н4 соответственно. В случае с двухцветными кремниевыми HЧ на образцах первичных опухолей, взятых у мышей, которым ввели контроль (H) или CGIYRLRS (O), кремниевые HЧ визуализируются как негативный контроль для дальнейшего использования. На рис. П (фрагмент поля на К) и $\mathbf{P}$ (фрагмент поля на М) представлены трехмерные модели, полученные из 50-80 конфокальных снимков с помощью программного обеспечения IMARIS. (По данным: Soster и др. [5].) 
аминполиэтиленгликоль, гидрогенизированный соевый фоссатидилхолин и холестерин. В такие стелс-липосомы (SL) был инкапсулирован доксорубицин (DXR) для получения наносистем направленного действия CPRECES-SL[DXR] и CNGRC-SL[DXR] соответственно, имеющих размеры 90-115 нм, инкапсуляцию препарата с выходом 95\% и показатель связывания пептидов 4 мкг/Мкмоль для каждой липосомы. Для проведения фармакокинетических исследований такие стелс-липосомы были снабжены двойной меткой путем встраивания 3Н и 14С в холестерин и доксорубицин соответственно, что позволило продемонстрировать достаточную стабильность и продолжительное время

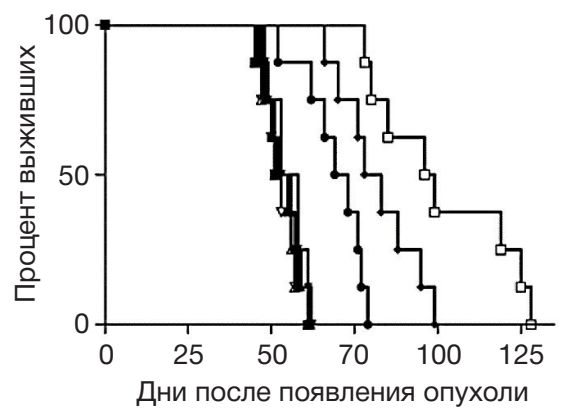

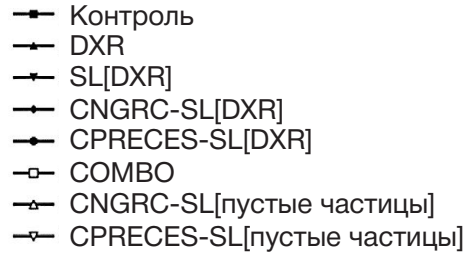

Рис. 3. Терапевтическая эффективность нацеленных на аминопептидазу N (APN) и A (APA) липосомных препаратов на модельных мышах с нейробластомой Бестимусные мыши (по 8 в группе), которым провели ортотопическую имплантацию клеток человеческой нейробластомы, начиная с 21-го дня после имплантации получали лечение с использованием буферного раствора HEPES (контроль), стелс-липосом CNGRC-SL[пустых], стелс-липосом CPRECES-

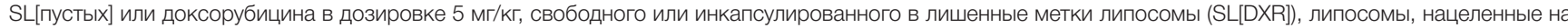
APN (CNGRC-SL[DXR]) или APA (CNGRC-SL[DXR]) или эквимолярную смесь CNGRC-SL[DXR] и CNGRC-SL[DXR] (COMBO), один раз в неделю в течение 5 недель. Эффективность каждого препарата оценивали по выживаемости, которая представлена на кривой Каплана-Майера в виде процента оставшихся в живых мышей для разных временных точек. (По данным: Loi и др. [18].)

A

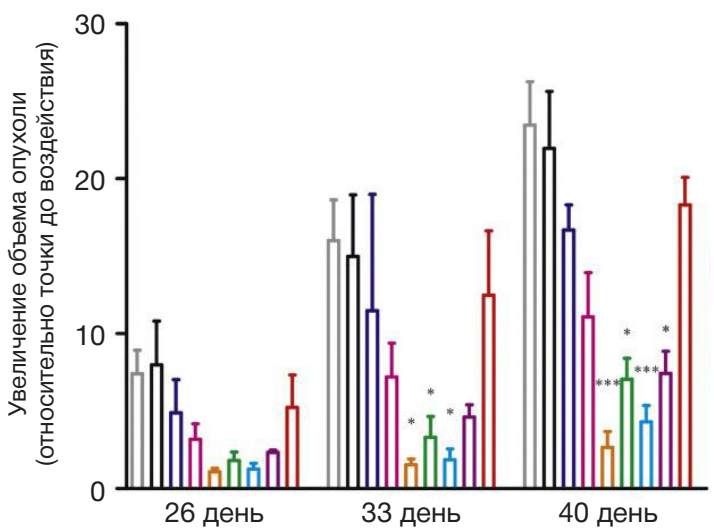

40 день
Рентгенограмма

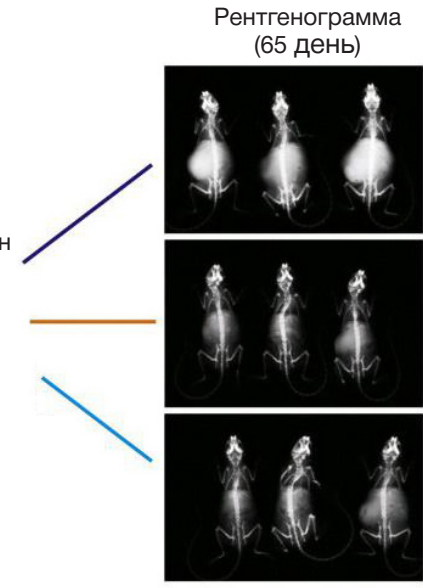

Б

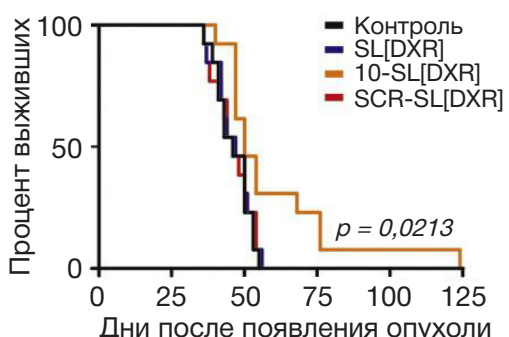

$\square$ Контроль

Свободный доксорубици

SL[DXR]

1-SL[DXR]

$\square$-SL[DXR]

8-SL[DXR]

10-SL[DXR]

14-SL[DXR]

SCR-SL[DXR]

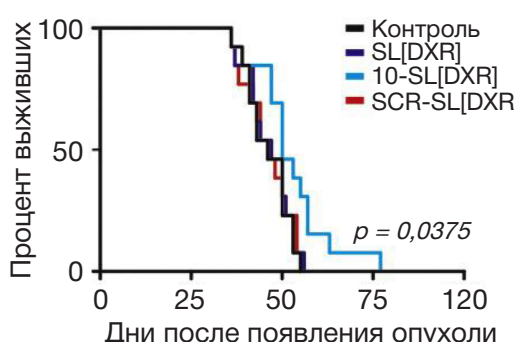

B
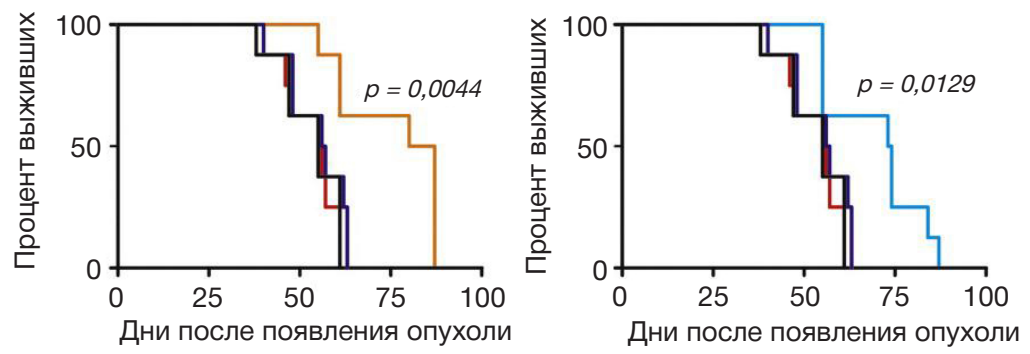

Рис. 4. А. Терапевтическая эффективность нацеленных на пептиды липосомных препаратов на модельных мышах, которым провели имплантацию экспрессирующих люцисеразу клеток человеческой неробластомы. Лечение начали через 21 день после имплантации опухоли. Мышам (по 5 в группе) внутривенно вводили буферный раствор HEPES (контроль) или доксорубицин в дозировке 5 мг/кг, свободный (free DXR) или инкапсулированный в лишенные метки стелс-липосомы (SL[DXR]), липосомы с пептидной смесью (SCR-SL[DXR] или усовершенствованные пептидами липосомы направленного действия (1-, 5-, 8-, 10-, 14-SL[DRX]), один раз в неделю в течение трех недель. Мониторинг роста опухоли проводили методом биослойной интерферометрии (ВL) через 5 дней после каждого эпизода получения лечения (26-й, 33-й, 40-й день с момента имплантации опухоли). Представлены значения увеличения объема опухоли по сравнению с днем, предшествовавшим началу лечения (20-й день). На рисунках представлены рентгеновские снимки, полученные через месяц после окончания лечения (65-й день), для мышей, получавших SL[DXR], 5-SL[DXR] и 10-SL[DXR] соответственно. Б-B. Терапевтический эффект препаратов направленного действия оценивали по общей выживаемости для псевдо-метастатической модели (13 животных в группе; Б) и для ортотопической модели (8 животных в группе; В). Статистический анализ: A, p vs. SL[DXR]; Б-B, p vs. контроль, SL[DXR] и SCR-SL[DXR]. (По данным: Loi и др. [16].) 
циркуляции (до 24 ч) [16]. Оценку эффективности этих композиций, как в виде одиночных агентов, так и в составе комбинированных препаратов (СОМВО), провели на ортотопических моделях, полученных в результате имплантации человеческих клеток нейробластомы в левый надпочечник бестимусных мышей. Начиная с 21-го дня после имплантации опухолевых клеток, мышам раз в неделю в течение 5 недель вводили доксорубицин (свободный или инкапсулированный в липосомы) в дозировке 5 мг/кГ; было показано, что введение CPRECES-SL[DXR], CNGRC$\mathrm{SL}[\mathrm{DXR}]$ или COMBO обеспечивало достоверное увеличение продолжительности жизни по сравнению с введением свободного препарата (до 17, 37 и 66 дней соответственно; рис. 3) [16].

\section{A}

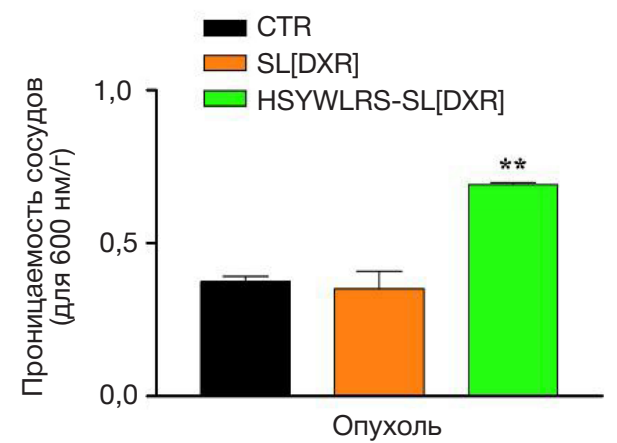

Б

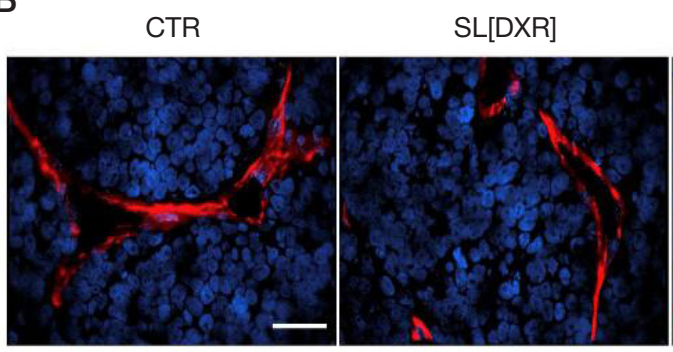

Данная работа демонстрирует, что нацеливание препарата на микросреду опухоли повышает его эффективность и потому может быть использовано для разработки инновационных лекарственных препаратов.

На основании этих вдохновляющих результатов были проведены комбинированные in vitro/ex vivo скрининги пептидных библиотек, полученных методом фагового дисплея с целью идентификации новых пептидных мотивов, высокоспецифичных для человеческой нейробластомы [16]. Эти эксперименты были поставлены, чтобы изолировать пептиды, способные связывать первичную опухоль целиком (обнаружено 26 мотивов) или скопление метастазов (15 мотивов), микросреду первичной опухоли (57 мотивов) или микросреду метастазов (23 мотива). Специсричность пяти
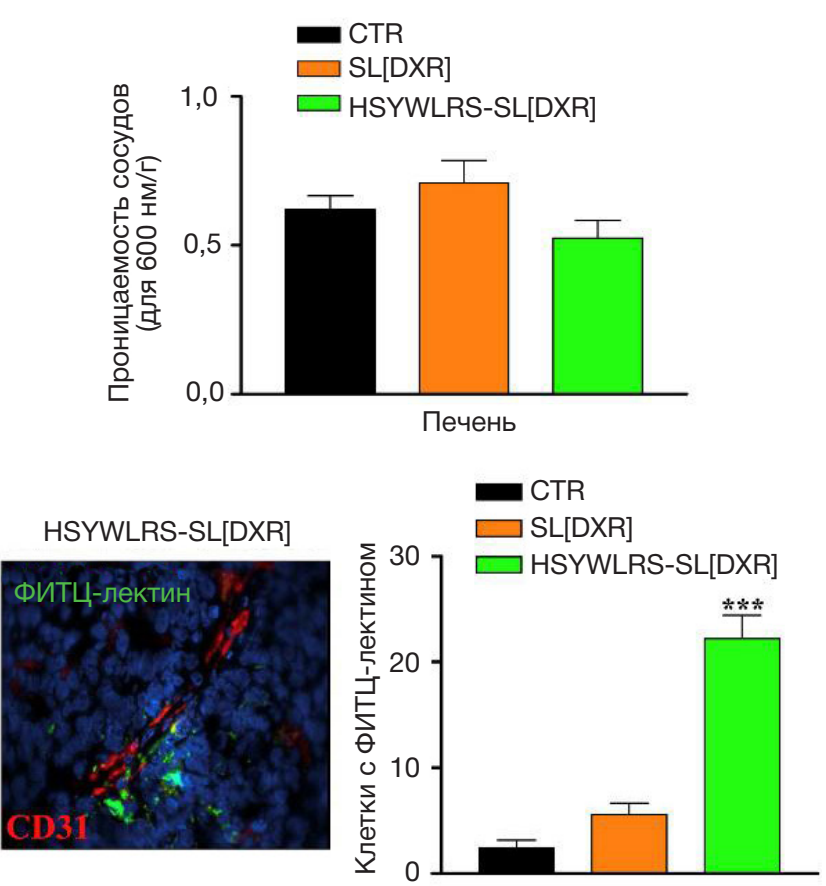

B

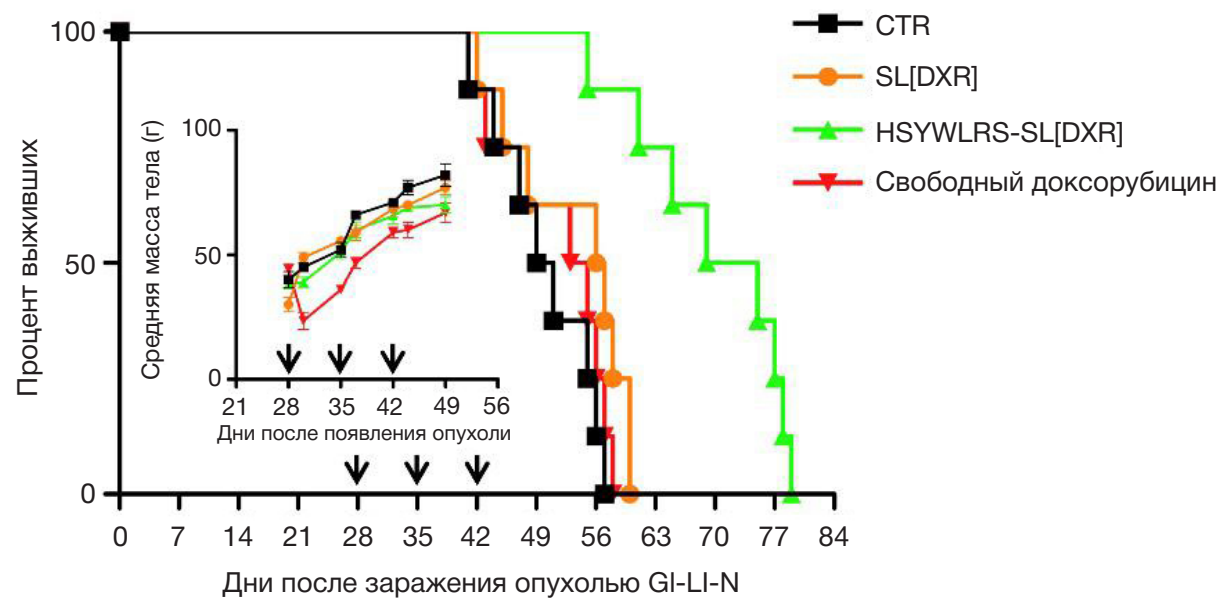

Рис. 5. А. Системная проницаемость in vivo. Мыши, имеющие ортотопические опухоли (по 3 в группе) 28 дней спустя получали одну дозу доксорубицина (5 мг/Kг), инкапсулированного в лишенные метки стелс-липосомы (SL[DXR]) или нацеленные на HSYWLRS липосомы (HSYWLRS-SL[DXR]), вместе с 1 мг голубого Эванса. Мыши из контрольной группы (CTR) получали только бусерный раствор НЕРЕS. Через час мышам выполняли перфузию, извлекали опухоли и печень, экстрагировали голубой Эванс и измеряли его количество (на 600 нм). Результаты выражены в количестве голубого Эванса на 1 г ткани. **, $p<0,01$ : HSYWLRS-SL[DXR] vs. контроль и SL[DXR]. Б. Примеры срезов опухолей мышей из контрольной группы или мышей, получавших SL[DXR] или HSYWLRS-SL[DXR], которым ввели ФИТЦ-лектин (зеленый). Красный: CD31. Синий: клеточные ядра (ДАПИ). Шкала: 40 мкм. На графике справа количество ФИТЦ-положительных клеток. ${ }^{* \star}, p<0,001$, HSYWLRS-SL[DXR] vs. контроль и SL[DXR]. В. Потенцированная терапевтическая эфрфективность HSYWLRS-SL[DXR]. Мышам (по 8 в группе), имеющим ортотопические опухоли, внутривенно вводили доксорубицин в дозировке 5 мг/кг, свободный или инкапсулированный в стелс-липосомы SL[DXR] и HSYWLRS-SL[DXR], один раз в неделю в течение 3 недель (стрелки). Мыши из контрольной группы (CTR) получали только бусерный раствор HEPES. Выживаемость: $p<0,0008$ : HSYWLRS-SL[DXR] vs. SL[DXR]). Вставка: средняя масса тела для разных временных точек. (По данным: Cossu и др. [17].) 
пептидов, нацеленных на скопление метастазов (фаговый клон \#14, пептидная последовательность KSFFLSH), микросреду первичной опухоли (\#1, YEGLISR) и микросреду метастазов (\#5, HSYWLRS; \#8, WSWPREL; \#10, ALAAHKL), была подтверждена ех vivo путем анализа связывания на срезах человеческой нейробластомы IV стадии и in vivo на модельных мышах. По этой причине пептиды синтезировали с присоединением N-концевого (YSHS, однобуквенный аминокислотный код) и С-концевого (GGG, однобуквенный аминокислотный код) доменов, связав их со стелслипосомами, как было описано выше [16]. Потенциальную эффективность таких наносистем исследовали на ортотопической модели, полученной в результате имплантации трансдуцированных люциферазой клеток человеческой нейробластомы. Кроме того, в результате введения опухолевых клеток в хвостовую вену бестимусных мышей была получена псевдо-метастатическая модель. Мыши после ортотопической имплантации получали лечение раз в неделю в течение трех недель, начиная с 21-го дня после имплантации опухолевых клеток, а мыши после внутривенной имплантации получали лечение по той же схеме, но начиная с 4-го часа после имплантации опухолевых клеток. В первой серии экспериментов наблюдение за ростом ортотопических опухолей, экспрессирующих люциферазу, осуществляли методом биолюминесцентной визуализации на 26-й, 33-й и 40-й дни после имплантации (через 5 дней после каждого эпизода получения лечения). 5-SL[DXR] и 10-SL[DXR] наиболее эффективно задерживали рост опухоли, что подтвердили результаты рентгенологического исследования всего тела, проведенного через месяц после окончания лечения (рис. 4A). Оценка способности препаратов направленного действия увеличивать продолжительность жизни мышей с опухолями была проведена последовательно на псевдо-метастатической (рис. 4Б) и ортотопической (рис. 4B) моделях. И снова лечение 5-SL[DXR] или 10-SL[DXR] продемонстрировало более высокую выживаемость мышей с нейробластомой по сравнению с контрольными животными и даже с животными, которых лечили доксорубицином, как свободным, так и инкапсулированным в липосомные препараты ненаправленного действия [16].

A
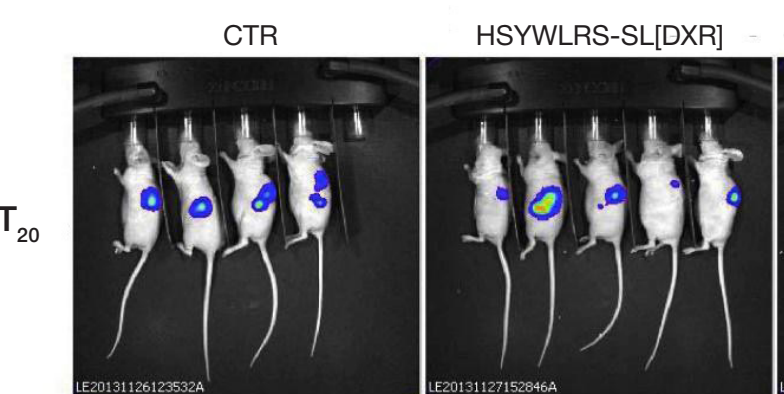

Свободный доксорубицин
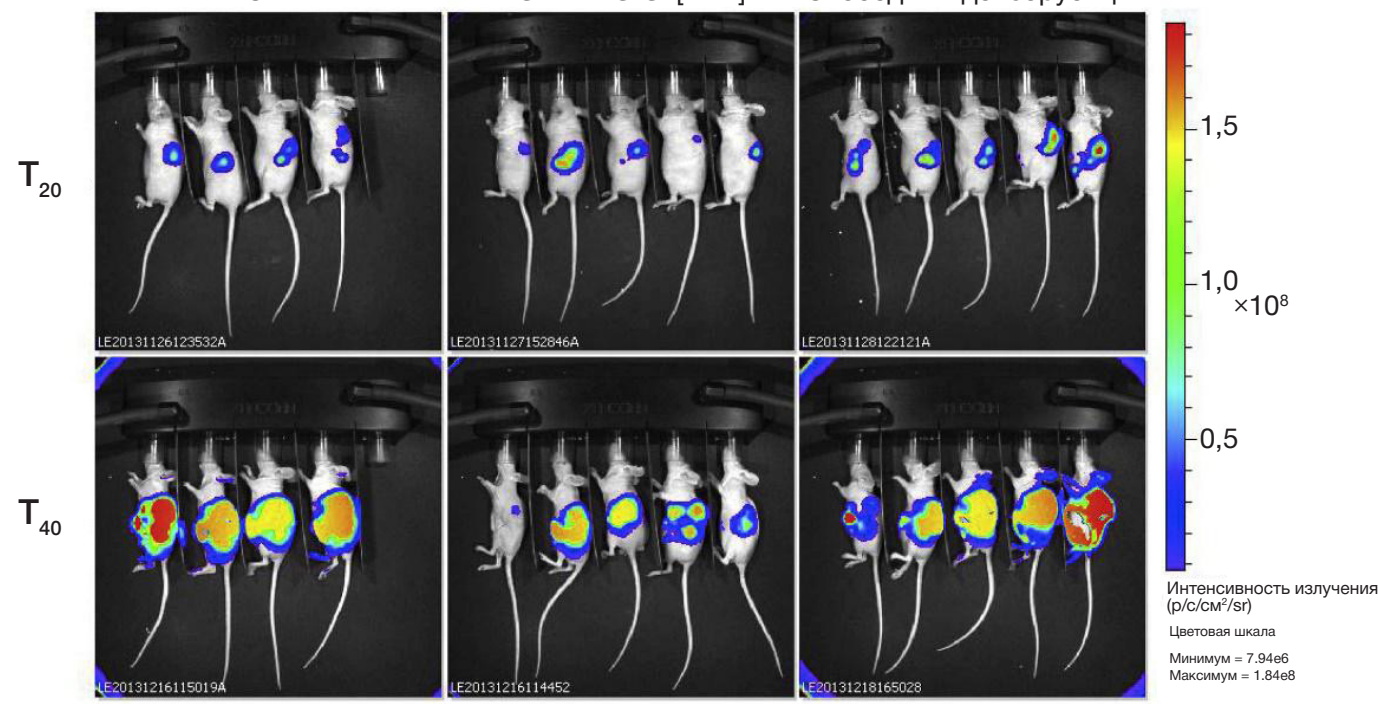

Б

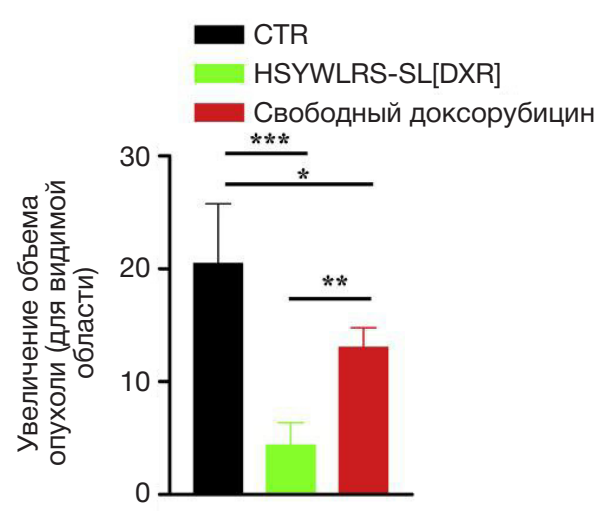

B

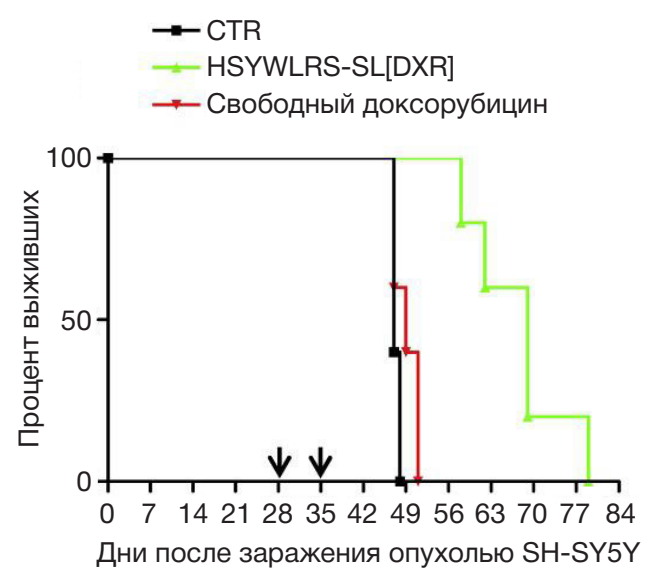

Рис. 6. А. Латеральные (со стороны опухоли) изображения мышей, которым была проведена ортотопическая имплантация экспрессирующих люциферазу клеток человеческой нейробластомы. Животные получали лечение внутривенно, один раз в неделю в течение 2 недель (стрелки), с использованием доксорубицина в дозировке 5 мг/кг - свободного (free DXR) или инкапсулированного в нацеленные на HSYWLRS липосомы (HSYWLRS-SL[DXR]). Mыши из контрольной группы (CTR) получали буферный раствор HEPES. Мониторинг роста опухоли проводили методом биослойной интерферометрии (ВLI) на 20-й день (перед началом лечения) и на 40-й день (окончание лечения) после появления опухоли. Б. Противоопухолевый эффект после окончания лечения, значение представлено как увеличение объема опухоли на 40-й день по сравнению с 20-м днем. *, $p<0,05:$ свободный доксорубицин vs. контроль; *夫, $p<0,01$ : HSYWLRS-SL[DXR] vs. свободный доксорубицин; ***, $p<0,001:$ HSYWLRS-SL[DXR] vs. контроль. B. HSYWLRS-SL[DXR] демонстрирует потенцированную терапевтическую эффективность. Выживаемость: $p<0,0025$ : HSYWLRS-SL[DXR] vs. контроль и свободный доксорубицин. (По данным: Соssu и др. [17].) 
Эти предварительные выводы были дополнены результатами последовательного углубленного изучения пептида HSYWLRS (\#5 из предыдущего исследования) как компонента направленного действия для доклинического применения [17]. Специфичность связывания и интернализации были подтверждены на дополнительных клеточных линиях, а также на образцах тканей модельных животных и человеческой нейробластомы IV стадии. Таким образом, снабженные пептидной меткой стелс-липосомь с инкапсулированным доксорубицином (HSWYLRSSL[DXR]) были созданы и исследованы как наносистемы для доставки препаратов in vivo. Оценка проницаемости сосудов была проведена путем введения голубого Эванса мышам с нейробластомой, получившим лечение HSYWLRS-SL[DXR], и отслеживания специфического повышения экстравазации красителя и аккумулирования в ортотопических опухолях, но не в неопухолевых тканях (рис. 5A). Лечение с помощью HSYWLRS-SL[DXR] также способствовало увеличению перфузии кровеносных сосудов опухолей, что было обнаружено в результате внутривенного введения лектин-флуоресцеин-изотиоцианата (ФИТЦ) и анализа испускаемой флуоресценции методом конфокальной микроскопии (рис. 5Б). Эти явления сопровождались: 1) увеличением аккумулирования HSYWLRS-SL[DXR] опухолью, но не доксорубицина, инкапсулированного в липосомные препараты ненаправленного действия; 2) увеличением продолжительности жизни животных (рис. 5В) при отсутствии признаков токсического воздействия, например потери веса (рис. 5В, на вставке). Кроме того, терапевтическую эффективность HSYWLRS-
SL[DXR] сравнили с терапевтической эффективностью свободного доксорубицина, пронаблюдав за ростом экспрессирующих люциферазу клеток человеческой нейробластомы после ортотопической имплантации in vivo методом биослойной интерферометрии, и обнаружили, что только липосомный препарат направленного действия вызывает эфффективный противоопухолевый ответ (рис. 6А-Б) и продлевает жизнь мышам с опухолями (рис. 6В). Этот эффект был подтвержден с помощью позитронно-эмиссионной томографии (ПЭТ) в сочетании с измерением поглощения глюкозы. Исследование показало, что лечение с помощью HSYWLRS-SL[DXR] существенно замедляет не только рост первичных опухолей, но и распространение вторичных опухолей (рис. 7А), что было подтверждено при аутопсии животных посредством определения количества метастатических очагов и общего объема метастазов (рис. 7В).

Bce эти данные подтверждают, что нацеленный на нейробластому пептид HSYWLRS может стать мощным средством для терапевтического применения.

\section{ВЫВОДЬ}

Весьма актуальна проблема ранней диагностики опухолей и эффективного лечения, которое имело бы максимальный противоопухолевый эффект, но не затрагивало нормальные ткани. Появление нанопрепаратов может радикально изменить наш подход к визуализации и лечению рака при условии, что мы идентифицируем обладающие подходящими свойствами биомаркеры. В действительности, несмотря

A

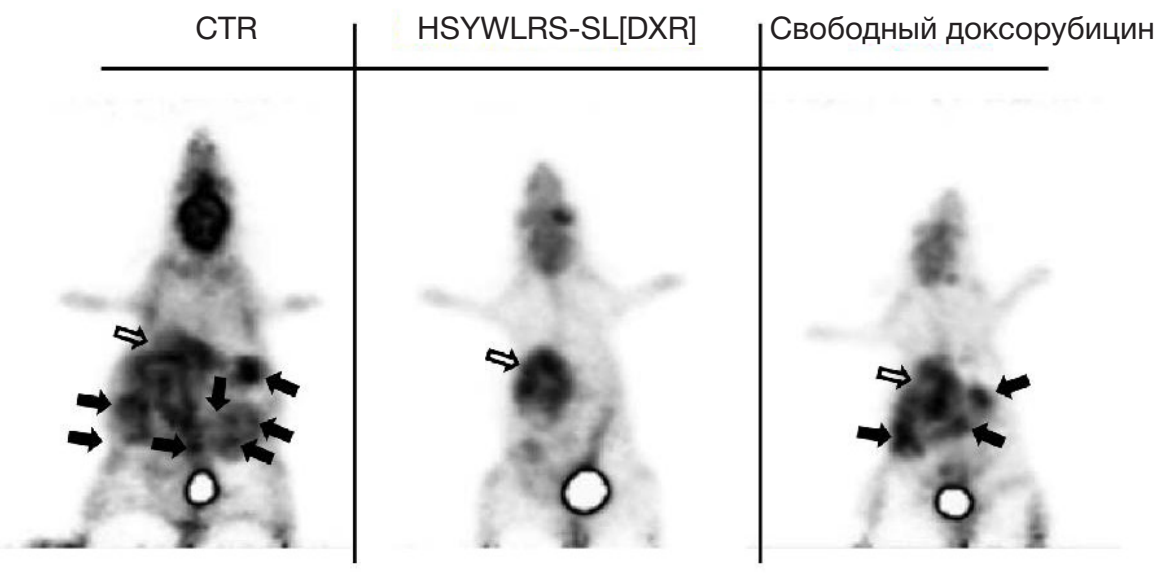

Б

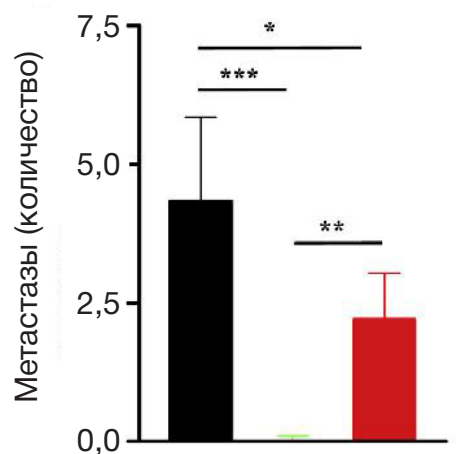

B

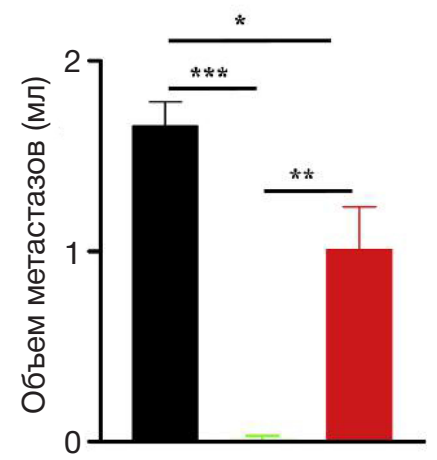

Рис. 7. Лечение с помощью HSYWLRS-SL[DXR] ингибирует вторичное распространение опухоли. Мыши (4 из контрольной группы, 5 получавших препарат), которым была проведена ортотопическая имплантация экспрессирующих люциферазу клеток человеческой нейробластомы, получали лечение, описанное в подписи к рис. 6. Оценка распространения опухоли была проведена методом ПЭТ через 41 день (А). Карты поглощения глюкозы (белые стрелки: первичная опухоль; черные стрелки: метастазы). Количество (Б) и объем метастазов (В) после лечения. *, p < 0,05: свободный доксорубицин vs. контроль; ${ }^{* *}, p<0,01:$ HSYWLRS-SL[DXR] vs. свободный доксорубицин; ${ }^{* * *}, p<0,001:$ HSYWLRS-SL [DXR] vs. контроль 
на то что разработка наноматериалов стремительно развивается, нам по-прежнему необходимы мишени с более высокой селективностью, чтобы сделать возможным применение ориентированных на пациента методов.
В нашей недавней работе обнаружен ряд мишеней и компонентов направленного действия лекарств, которые были проверены доклинически и могут быть использованы для дальнейшей разработки клинических методов.

\section{Литература}

1. Arap W, Pasqualini R, Montalti M, Petrizza L, Prodi L, Rampazzo E et al. Luminescent silica nanoparticles for cancer diagnosis. Curr Med Chem. 2013; 20 (17): 2195-211.

2. Bobo D, Robinson KJ, Islam J, Thurecht KJ, Corrie SR. Nanoparticle-based medicines: a review of FDA-approved materials and clinical trials to date. Pharm Res. 2016; 33 (10): 2373-87.

3. Caster JM, Patel AN, Zhang T, Wang A. Investigational nanomedicines in 2016: a review of nanotherapeutics currently undergoing clinical trials. Rev Nanomed Nanobiotechnol. 2017; 9 (1): e1456.

4. Marchiò S, Soster M, Cardaci S, Muratore A, Bartolini A, Barone V et al. A complex of alpha(6) integrin and E-cadherin drives liver metastasis of colorectal cancer cells through hepatic angiopoietinlike 6. EMBO Mol Med. 2012 Nov; 4 (11): 1156-75.

5. Soster M, Juris R, Bonacchi S, Genovese D, Montalti M, Rampazzo E et al. Targeted dual-color silica nanoparticles provide univocal identification of micrometastases in preclinical models of colorectal cancer. Int J Nanomed. 2012; (7): 4797-807.

6. Bonacchi S, Genovese D, Juris R, Montalti M, Prodi L, Rampazzo E et al. Luminescent chemosensors based on silica nanoparticles. Top Curr Chem. 2011; (300): 93-138.

7. Bonacchi S, Genovese D, Juris R, Montalti M, Prodi L, Rampazzo E et al. Luminescent silica nanoparticles: extending the frontiers of brightness. Angew Chem Int Ed Engl. 2011; 50 (18): 4056-66.

8. D'Hallewin MA, Kamuhabwa AR, Roskams T, De Witte PA, Baert L. Hypericin-based fluorescence diagnosis of bladder carcinoma. BJU Int. 2002; 89 (7): 760-3.

9. Miyashiro I, Miyoshi N, Hiratsuka M, Kishi K, Yamada T, Ohue M et al. Detection of sentinel node in gastric cancer surgery by indocyanine green fluorescence imaging: comparison with infrared imaging. Ann Surg Oncol. 2008; 15 (6): 1640-3.

10. van Dam GM, Themelis G, Crane LM, Harlaar NJ, Pleijhuis RG, Kelder $W$ et al. Intraoperative tumor-specific fluorescence imaging

\section{References}

1. Arap W, Pasqualini R, Montalti M, Petrizza L, Prodi L, Rampazzo E et al. Luminescent silica nanoparticles for cancer diagnosis. Curr Med Chem. 2013; 20 (17): 2195-211.

2. Bobo D, Robinson KJ, Islam J, Thurecht KJ, Corrie SR Nanoparticle-based medicines: a review of FDA-approved materials and clinical trials to date. Pharm Res. 2016; 33 (10): 2373-87.

3. Caster JM, Patel AN, Zhang T, Wang A. Investigational nanomedicines in 2016: a review of nanotherapeutics currently undergoing clinical trials. Rev Nanomed Nanobiotechnol. 2017; 9 (1): e1456.

4. Marchiò S, Soster M, Cardaci S, Muratore A, Bartolini A, Barone V et al. A complex of alpha(6) integrin and E-cadherin drives liver metastasis of colorectal cancer cells through hepatic angiopoietinlike 6. EMBO Mol Med. 2012 Nov; 4 (11): 1156-75.

5. Soster $M$, Juris R, Bonacchi S, Genovese D, Montalti $M$, Rampazzo E et al. Targeted dual-color silica nanoparticles provide univocal identification of micrometastases in preclinical models of colorectal cancer. Int J Nanomed. 2012; (7): 4797-807.

6. Bonacchi S, Genovese D, Juris R, Montalti M, Prodi L, Rampazzo E et al. Luminescent chemosensors based on silica nanoparticles. Top Curr Chem. 2011; (300): 93-138.

7. Bonacchi S, Genovese D, Juris R, Montalti M, Prodi L, Rampazzo E et al. Luminescent silica nanoparticles: extending the frontiers of

brightness. Angew Chem Int Ed Engl. 2011; 50 (18): 4056-66.

8. D'Hallewin MA, Kamuhabwa AR, Roskams T, De Witte PA, Baert L. Hypericin-based fluorescence diagnosis of bladder carcinoma. BJU Int. 2002; 89 (7): 760-3.

9. Miyashiro I, Miyoshi N, Hiratsuka M, Kishi K, Yamada T, Ohue M et al. Detection of sentinel node in gastric cancer surgery by indocyanine green fluorescence imaging: comparison with infrared imaging. Ann Surg Oncol. 2008; 15 (6): 1640-3.

10. van Dam GM, Themelis G, Crane LM, Harlaar NJ, Pleijhuis RG, Kelder W et al. Intraoperative tumor-specific fluorescence imaging in ovarian cancer by folate receptor-alpha targeting: first in-human results. Nat Med. 2011; 17 (10): 1315-9.

11. van der Poel HG, Buckle T, Brouwer OR, Valdes Olmos RA, van Leeuwen FW. Intraoperative laparoscopic fluorescence guidance to the sentinel lymph node in prostate cancer patients: clinical proof of concept of an integrated functional imaging approach using a multimodal tracer. Eur Urol. 2011; 60 (4): 826-33.

12. de Leeuw J, van der Beek N, Neugebauer WD, Bjerring P, Neumann HA. Fluorescence detection and diagnosis of nonmelanoma skin cancer at an early stage. Lasers Surg Med. 2009; 41 (2): 96-103.

13. Atlamazoglou V, Yova D, Kavantzas N, Loukas S. Microscopical examination of the localisation patterns of two novel rhodamine derivatives in normal and neoplastic colonic mucosa. Lasers Med 
Sci. 2001; 16 (4): 253-9.

14. Marchiò S, Lahdenranta J, Schlingemann RO, Valdembri D, Wesseling P, Arap MA et al. Aminopeptidase A is a functional target in angiogenic blood vessels. Cancer Cell. 2004; 5 (2): 151-62.

15. Pasqualini R, Koivunen E, Kain R, Lahdenranta J, Sakamoto M, Stryhn A. Aminopeptidase $\mathrm{N}$ is a receptor for tumor-homing peptides and a target for inhibiting angiogenesis. Cancer Res. 2000; 60 (3): 722-7.

16. Loi M, Di Paolo D, Soster M, Brignole C, Bartolini A, Emionite L et al. Novel phage display-derived neuroblastoma-targeting peptides potentiate the effect of drug nanocarriers in preclinical settings. J Control Release. 2013; 170 (2): 233-41.

17. Cossu I, Bottoni G, Loi M, Emionite L, Bartolini A, Di Paolo D et al. Neuroblastoma-targeted nanocarriers improve drug delivery and penetration, delay tumor growth and abrogate metastatic diffusion. Biomaterials. 2015; (68): 89-99.

18. Loi M, Marchiò S, Becherini P, Di Paolo D, Soster M, Curnis F et al. Combined targeting of perivascular and endothelial tumor cells enhances anti-tumor efficacy of liposomal chemotherapy in neuroblastoma. J Control Release. 2010; 145 (1): 66-73. 